\title{
CONGENITAL CHOANAL ATRESIA: A CASE SERIES
}

\section{Dr. Mainak Maitra*}

Junior Resident, Department of ENT \& Head Neck Surgery, R. G. Kar Medical College \& Hospital, 1, Khudiram Bose Sarani, Kolkata 700004. ${ }^{*}$ Corresponding Author

\section{Dr. Mukesh Kumar} Singh
Assistant Professor, Department of ENT \& Head Neck Surgery, R.G. Kar Medical College \& Hospital, 1, Khudiram Bose Sarani, Kolkata-700004.

ABSTRACT choanal atresia is 2.2. Approximately two-thirds of cases are unilateral. Structurally there are two main types- a) Osseous-90\% b) Membranous. Bilateral CA is an important but rare cause of respiratory distress in newborn. The distress improves with an oral airway. Here 3 paediatric cases of congenital choanal atresia are being discussed. Choanal atresia as a differential diagnosis should always be kept in mind in children presenting with respiratory distress in early neonatal period and in patients presenting with unilateral nasal discharge. Endoscopic surgical technique of choanal atresia repair along with stenting was done in all the 3 cases.

KEYWORDS : Choanal Atresia, Neonate, Computed Tomography (CT), Diagnostic Nasal Endoscopy (DNE)

\section{INTRODUCTION}

Congenital Choanal Atresia (CA) is the failure in the development in communication between the nasal cavity and the nasopharynx causing complete obstruction of the choana.. It's incidence is 1 in 7000 birth ${ }^{[1]}$. The male to female ratio for infants with choanal atresia is $2.2^{[2]}$. Approximately two-thirds of cases are unilateral ${ }^{[3]}$. Structurally there are two main types-a) Osseous- $90 \%{ }^{[4]}$ b) Membranous. Bilateral CA is an important but rare cause of respiratory distress in newborn. The distress improves with an oral airway ${ }^{[5]}$.

Associated defects largely occurred in a predictable pattern described by the CHARGE pnemonic : C-Coloboma, H- Heart disease, A-Atresia of the choana,R- Retarded growth,GGenital hypoplasia,E-Ear defects ${ }^{[6]}$.

3 cases of congenital choanal atresia that was managed at a tertiary care hospital are being elaborated as follows.

CASE No. 1

A 14 day old female neonate born to a primi gravida at 39 weeks of gestation delivered by emergency caesarean section was referred from the neonatal intensive care unit for otorhinolaryngological examination with complaints of respiratory distress since birth which improved during episodes of crying and mucoid secretion from bilateral nostrils. On clinical examination, it was found that the respiratory distress improved in prone position and during episodes of crying. Attempts of mouth breathing were also noted. Infant feeding tube couldn't be passed through either of the nostrils which raised the suspicion of bilateral choanal atresia. Diagnostic Nasal Endoscopy (DNE) was done after thorough suctioning of both nasal cavities. DNE revealed absence of bilateral choanal openings. Other anatomical structures were found to be normal on nasal endoscopy. Computed Tomography (CT) scan of the nose and the paranasal sinuses showed presence of osseous crowding near both the choana pointing towards a diagnosis of bilateral congenital atresia (bony type). Other systemic examinations revealed no abnormalities.

\section{Management :}

Initially the neonate was managed with the help of an oral airway during the course of the preoperative investigations. The patient was then taken up for Endoscopic choanal atresia repair under general anaesthesia after pre-anaesthetic checkup. After proper suctioning and decongestion of the nasal cavity, the atretic plate was identified on both sides. Then incision was made on the mucosa overlying the right atretic plate ${ }^{[7]}$. Subsequently, mucosal flaps were raised to expose the underlying bone (Figure 1). The infero-medial aspect of the bony plate was thinned out using microdrill ${ }^{[7]}$ and an opening was made which was widened with blunting of the sharp edges with the help of the microdrill ${ }^{[7]}$. Posterior half of the septum including the vomer was removed using the Blakesley forcep ${ }^{[8]}$. Laterally the opening was widened until the neurovascular bundle of the greater palatine artery was exposed[8]. The superior boundary of the neochoana was the floor of the sphenoid sinus ${ }^{[8]}$. The inferior boundary was flushed with the nasal floor ${ }^{[8]}$ (Figure 2). The same procedure was repeated on the left side. This was followed by stenting of bilateral neochoana by endoscopic guidance ${ }^{[9]}$ using endotracheal tube (Figure 3). The stents were kept in situ for 4 weeks ${ }^{[10]}$. The child was followed up till 12 weeks after removal of stent with normal saline nasal irrigation, regular endoscopic examination along with removal of crusts at weekly intervals. There was no evidence of neochoanal stenosis till 12 weeks after stent removal after which he patient was lost to follow up.

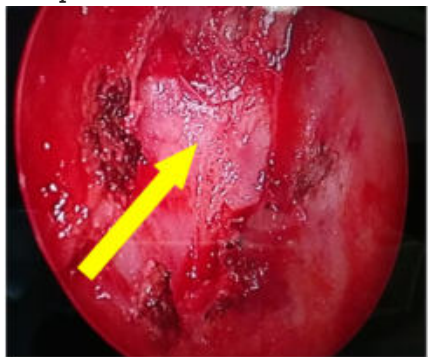

Figure 1.

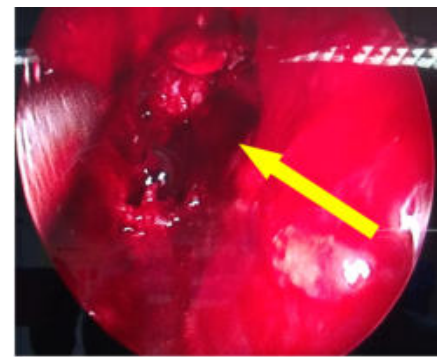

Figure 2. 


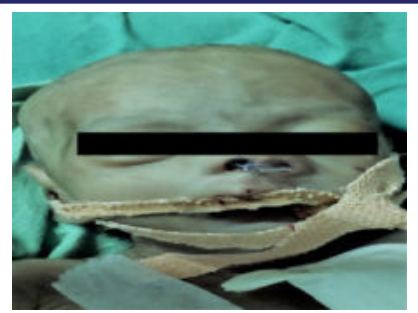

Figure 2.

CASE No. 2

A 10 year old child attended the outpatient department of ENT with complaints of recurrent right sided mucoid nasal discharge for last 2 years. He had sought medical advice before from other centres but the conservative management of nasal wash and sprays didn't provide him with any relief. On DNE, plenty of mucoid secretions was found in the right nasal cavity which was suctioned out. However, choanal opening couldn't be identified on the right side of the nasal cavity (Figure 4). Left side nasal cavity didn't reveal any abnormality. Further CT scan of Nose and paranasal sinuses done after thorough suctioning of the nose revealed right sided unilateral congenital choanal atresia (Bony type)(Figure 5). Other systemic examinations revealed no abnormalities.

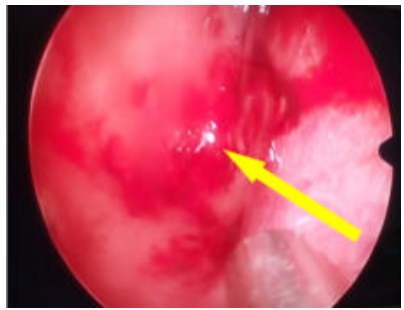

Figure 4.

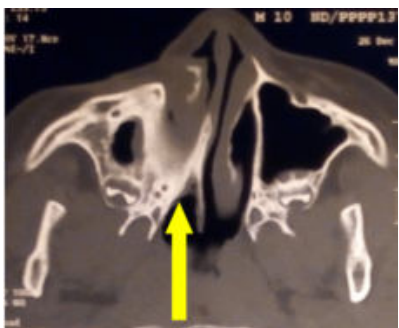

Figure 5.

Management :

The patient was then taken up for Endoscopic choanal atresia repair under general anaesthesia after pre-anaesthetic checkup. After proper suctioning and decongestion of the nasal cavity, the atretic plate was identified on right side. Then neochoana was made using microdrill in a way similar to Case number l. This was followed by stenting of right neochoana by endoscopic guidance ${ }^{[9]}$ using endotracheal tube (Figure 6).

The stents were kept in situ for 4 weeks ${ }^{[10]}$.

The child was followed up till 24 weeks after removal of stent with normal saline nasal irrigation, regular endoscopic examination along with removal of crusts at weekly intervals (Figure 7). There was no neochoanal stenosis till the last follow up.

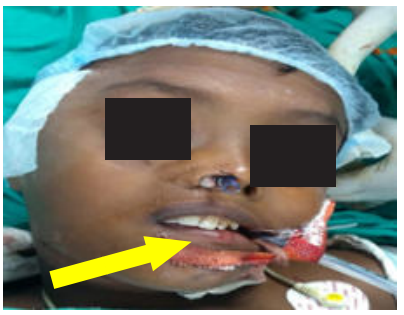

Figure 6.

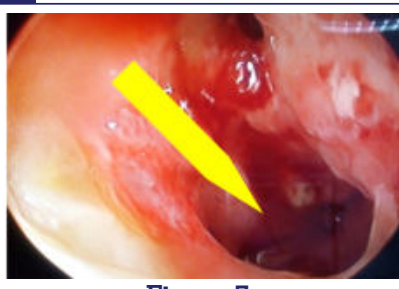

Figure 7.

CASE No. 3

A 3 year old male child was brought to the outpatients department of ENT of the tertiary care hospital with complaint of right sided foul smelling nasal discharge for last 2 weeks. On clinical examination there was presence of foul smelling mucopurulent discharge in the right nasal cavity. The child was taken up for DNE under sedation with a possibility of a neglected foreign body in the right nasal cavity. However, after thorough suction clearance of the nasal cavity on the right side, no foreign body was found; instead there was a partition in the region of right choana. CT scan of nose and paranasal sinuses confirmed the presence of right sided congenital choanal atresia (mixed variety)(Figure 8). Other systemic examinations ruled out CHARGE association.

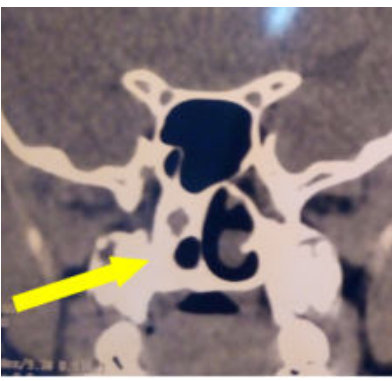

Figure 8.

\section{Management :}

The patient was then taken up for Endoscopic choanal atresia repair under general anaesthesia after pre-anaesthetic checkup in a separate sitting. After proper suctioning and decongestion of the nasal cavity, the atretic plate was identified on right side. Then neochoana was made using microdrill in a way similar to Case number 1 . This was followed by stenting of right neochoana by endoscopic guidance [9] using endotracheal tube.

The stents were kept in situ for 4 weeks ${ }^{[10]}$.

The child was followed up till 16 weeks after removal of stent with normal saline nasal irrigation, regular endoscopic examination along with removal of crusts at weekly intervals. The patient was lost to follow up thereafter. Till the last followup there was no evidence of neochaonal stenosis.

\section{DISCUSSION}

The incidence of Choanal Atresia is 1 in 7000 births[1]. Structurally there are two main types- a) Osseous- $90 \%{ }^{[4]}$ b) Membranous-10\%. But, a detailed review of CT imaging combined with histopathological studies has shown mixed bony-membranous atresia to be most common, accounting for $71 \%$ of congenital choanal atresia cases compared with pure bony atresia found in $29 \%{ }^{[11]}$. In our study with 3 cases, 2 cases had bony atresia while only l case had mixed atresia.

The male to female ratio for infants with choanal atresia is $2.2^{[2]}$. The only infant in our case series was a female. The remaining 2 children were males. Computed Tomography (CT) scans in all the 3 patients were done to avoid false CT findings of a meningoencephalocoele due to chondrocranium $[12,13]$

The surgical technique followed was similar to a number of 
previous studies in the literature ${ }^{[7,8]}$. The role of stenting at the end of surgery is controversial. In all the 3 cases in this case series, stenting was done using endotracheal tube. Some studies reveal good results with stenting of the neochoan ${ }^{[10,14]}$. Wolf et al. reported that the usage of stent was the ideal treatment of choice for neonates to avoid restenosis and other complications $^{[15]}$. A metaanalysis by Strychowsky et al. reported similar success outcomes with and without stenting ${ }^{[16]}$. In our study, all the cases had stents in situ for 4 weeks. Some studies by Nithyasundar \& Narayanan and Gupta \& Kour favored 4 weeks of stenting ${ }^{[10,1]}$. In all the 3 cases, there was no neochoanal stenosis till the follow up of 12 weeks, 24 weeks \& 16 weeks respectively.

\section{CONCLUSIONS}

Choanal atresia though an uncommon condition should be kept in differential diagnosis in children presenting with respiratory distress at birth and with unilateral nasal discharge. Endoscopic surgical management is the preferred modality of treatment, though the use of stent is controversial.

\section{LIMITATIONS}

1. Small sample size

2. Short follow up period because all 3 patients lost to follow up for longer durations.

\section{REFERENCES:}

1. Gujrathyi CS, Daniel SJ, James AL, Forte V. Management of Bilateral choanal atresia in the neonate: an institutional review. Int J Pediatr Otorhinolaryngol 2004;68(4):399-407

2. Michalski AM, Richardson SD, Browne ML,et al. Sex ratio among infants with birth defects, National Birth Defects Prevention Study,1997-2009.Am J Med Genet A.2015 May 167A(5):1071-81

3. Hengerer AS, Brickman TM, Jeyakumar A. Choanal atresia: embryologic analysis and evolution of treatment, a 30 year experience. Laryngoscope 2008;118(5):862-6

4. Lowe LH, Booth TN, Joglar JM et-al. Midface anomalies in children. Radiographics.20(4):907-22

5. SSP KHOPE,HG KAMAT,GV PAI BHALE. Bilateral Choanal AtresiaEmergency Neonatal Transpalatine Repair. J Indian Assoc PEDIATR SURG VOL-8(OCT-DEC 2003): 245

6. Naidich TP, Takahashi S, Tobin RB. Normal patterns of ossification of the skull base: ages 0-16yrs.

7. Stankiewicz JA. The endoscopic repair of choanal atresia. Otolaryngol Head Neck Surg. 1990 Dec;103(6):931-7. doi: 10.1177/019459989010300608. PMID: 2126127.

8. Wormald PJ, Zhao YC, Valdes CJ, et al. The endoscopic transseptal approach for choanal atresia repair. Int Forum Allergy Rhinol. 2016;6:654-660.

9. Park $\mathrm{AH}$, Brockenbrough J, Stankiewicz J: Endoscopic versus traditional approaches to choanal atresia. Otolaryngol Clin North Am. 2000, 33:77-90. 10.1016/S0030-6665(05)70208-5

10. Nithyasundar $A$, Narayanan DS: Choanal atresia: experience with transnasal endoscopic technique. J Pharm Sci Res. 2016, 8:86-87.

11. Brown OE, Pownell P, Manning SC. Choanal atresia: a new anatomic classification and clinical management applications. Laryngoscope. 1996; 106:97-101.

12. Guilherme P Buzatto,Ricardo S.Oliveira,Wilma T.Anselmo-lima,FabianaC.P. Valera.Choanal atresia misdiagnosed as encephalocoele:Int J Pediatr Otorhinolaryngol Ex Vol (6),2011:343-350

13. Elsheikh E,El-Anwar MW.False Computed Tomography Findings in Bilateral Choanal Atresia;Int Arch Otorhinolaryngol 2016;20:163-165

14. Rodríguez H, Cuestas G, Passali D: A 20-year experience in microsurgical treatment of choanal atresia [Article in English. Spanish]. Acta Otorrinolaringol. 2014,65:85-92. 10.1016/j.otoeng.2013.09.001

15. Wolf A, Lang.Loidolt D, Koele W, Wolf G, Thurnher D, Stammberger H, Tomazic PV: Are stents beneficial in endoscopic choanal atresia repair of newborns and children? Case series of 11 patients. Clin Otolaryngol. 2016, 41:821-825. 10.1111/coa.12566

16. Strychowsky JE, Kawai K, Moritz E, Rahbar R, Adil EA. To stent or not to stent? A meta-analysis of endonasal congenital bilateral choanal atresia repair. Laryngoscope. 2016 Jan;126(1):218-27. doi: 10.1002/lary.25393. Epub 2015 May 25. PMID: 26014684.

17. Gupta M, Kour C: Congenital bilateral choanal atresia: a rare case . J Rare Disor Diagn Therap. 2017, 3:9. 10.21767/2380-7245.100162 